\title{
Erratum: Cheng, Y.-C., et al. Evidence Supports PA Prescription for Parkinson's Disease: Motor Symptoms and Non-Motor Features: A Scoping Review. Int. J. Environ. Res. Public Health 2020, 17,2894
}

\author{
Yi-Chen Cheng ${ }^{1,2}$ (D) and Chun-Hsien Su ${ }^{1,2, *(D)}$ \\ 1 Department of Exercise and Health Promotion, College of Education, Chinese Culture University, \\ Taipei City 11114, Taiwan; cyz29@ulive.pccu.edu.tw \\ 2 Graduate Institute of Sport Coaching Science, College of Education, Chinese Culture University, \\ Taipei City 11114, Taiwan \\ * Correspondence: chsu@faculty.pccu.edu.tw; Tel.: +886-975-159-678
}

Received: 30 June 2020; Accepted: 11 July 2020; Published: 13 July 2020

The authors wish to make the following corrections to their paper published in IJERPH [1]: authors' affiliation.

[Old author's name and affiliation]:

1 Department of Exercise and Health Promotion, Colleage of Education, Chinese Culture University, Taipei City 11114, Taiwan; cyz29@ulive.pccu.edu.tw

2 Graduate Institude of Sport Coaching Science, Colleage of Education, Chinese Culture University, Taipei City 11114, Taiwan

* $\quad$ Correspondence: chsu@faculty.pccu.edu.tw; Tel.: +886-975-159-678

to the correct version, as follows:

[New Author's name and affiliations]:

1 Department of Exercise and Health Promotion, College of Education, Chinese Culture University, Taipei City 11114, Taiwan; cyz29@ulive.pccu.edu.tw

2 Graduate Institute of Sport Coaching Science, College of Education, Chinese Culture University, Taipei City 11114, Taiwan

* $\quad$ Correspondence: chsu@faculty.pccu.edu.tw; Tel.: +886-975-159-678

The authors would like to apologize for any inconvenience caused to the readers by these changes.

\section{References}

1. Cheng, Y.-C.; Su, C.-H. Evidence Supports PA Prescription for Parkinson's Disease: Motor Symptoms and Non-Motor Features: A Scoping Review. Int. J. Environ. Res. Public Health 2020, 17, 2894. [CrossRef] [PubMed]

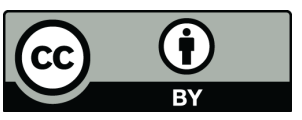

(C) 2020 by the authors. Licensee MDPI, Basel, Switzerland. This article is an open access article distributed under the terms and conditions of the Creative Commons Attribution (CC BY) license (http://creativecommons.org/licenses/by/4.0/). 